\title{
CONSULTA DE ENFERMAGEM A FAMÍLIA DA CRIANÇA COM INCONGRUÊNCIA DE GÊNERO
}

\author{
Paula Fernanda Lopes \\ Doutoranda da Faculdade de Enfermagem \\ Universidade Estadual de Campinas. \\ paula feerd@hotmail.com
}

INTRODUÇÃO: A literatura de enfermagem é silenciosa em relação ao cuidado a crianças com incongruência de gênero, o que contribui para incertezas sobre como interagir com elas e suas famílias. É importante a criação de um instrumento para guiar o enfermeiro na consulta e implementar o processo de enfermagem a família. OBJETIVO: Apresentar a experiência da construção de instrumento para consulta de enfermagem a família da criança com incongruência de gênero em ambulatório de hospital universitário. MÉTODO: A elaboração do instrumento foi baseada no Modelo Calgary de Avaliação Familiar, apoiada na taxonomia dos diagnósticos, intervenções e resultados da Associação Norte Americana de Diagnósticos de Enfermagem, entre outubro de 2017 e março de 2018. RESULTADOS: O instrumento inicia com a descrição do motivo da consulta e apreende o discurso familiar. Na avaliação estrutural, realiza-se caracterização da família por meio do genograma e ecomapa, que compreende a estrutura interna. Na estrutura externa, são elencados os laços sociais da criança. A avaliação do desenvolvimento relata 0 ciclo vital da família. A avaliação funcional descreve o cotidiano e como membros da família enfrentam situações de exposição de emoções e sentimentos decorrentes das mudanças comportamentais da criança. Ao final são apresentados os diagnósticos, resultados e intervenções de enfermagem.

CONSIDERAÇÕES FINAIS: A utilização desse instrumento possibilitou ao enfermeiro a avaliação dos pontos fortes e o reconhecimento dos problemas familiares, embasando a tomada de decisão e o estabelecimento do processo de enfermagem. A contribuição desse estudo para a prática clínica é direcionar o cuidado e fortalecer a participação do enfermeiro nesse tipo de ambulatório.

Palavras-chave: Incongruência de gênero. Crianças com incongruência de gênero. Implementação do processo de enfermagem a família. 